\title{
BMJ Global Health
}

\section{'We lost because of his drunkenness': the social processes linking alcohol use to self-harm in the context of daily life stress in marriages and intimate relationships in rural Sri Lanka}

\author{
Jane Brandt Sørensen, ${ }^{1}$ Thilini Agampodi, ${ }^{2}$ Birgitte Refslund Sørensen, ${ }^{3}$ \\ Sisira Siribaddana, ${ }^{4}$ Flemming Konradsen, ${ }^{1}$ Thilde Rheinländer ${ }^{1}$
}

To cite: Sørensen JB, Agampodi T, Sørensen BR, et al. 'We lost because of his drunkenness': the social processes linking alcohol use to self-harm in the context of daily life stress in marriages and intimate relationships in rural Sri Lanka. BMJ Glob Health 2017;2:e000462. doi:10.1136/ bmjgh-2017-000462

Handling editor Stephanie Topp

Received 7 July 2017

Revised 20 September 2017 Accepted 22 September 2017

\section{(a) CrossMark}

${ }^{1}$ Department of Public Health, University of Copenhagen, Copenhagen, Denmark ${ }^{2}$ Department of Community Medicine, Faculty of Medicine and Allied Sciences, Rajarata University of Sri Lanka, Saliyapura, Sri Lanka ${ }^{3}$ Department of Anthropology, University of Copenhagen, Copenhagen, Denmark ${ }^{4}$ Department of Medicine, Faculty of Medicine and Allied Sciences, Rajarata University of Sri Lanka, Saliyapura, Sri Lanka

\section{Correspondence to} Jane Brandt Sørensen, Department of Public Health, University of Copenhagen, Copenhagen, Denmark; janebs@sund.ku.dk

\begin{abstract}
Introduction Harmful alcohol use has been found to cause detriment to the consumers and those around them. Research carried out in Sri Lanka has described the socioeconomic consequences to families owing to alcohol consumption. However, the social processes around alcohol use and how it could result in behaviour such as self-harm was unclear. With an outset in daily life stressors in marriages and intimate relationships we explored alcohol use in families with a recent case of self-harm.
\end{abstract}

Methods Qualitative data were collected for 11 months in 2014 and 2015 in the North Central and North Western provinces of Sri Lanka. Narrative life story interviews with 19 individuals who had self-harmed where alcohol was involved and 25 of their relatives were conducted. Ten focus group discussions were carried out in gender and age segregated groups. An inductive content analysis was carried out.

Results Participants experienced two types of daily life stressors: non-alcohol-related stressors, such as violence and financial difficulties, and alcohol-related stressors. The alcohol-related stressors aggravated the non-alcohol-related daily life stressors within marriages and intimate relationships, which resulted in conflict between partners and subsequent self-harm. Women were disproportionately influenced by daily life stressors and were challenged in their ability to live up to gendered norms of marriage. Further, women were left responsible for their own and their husband's inappropriate behaviour. Self-harm appeared to be a possible avenue of expressing distress. Gendered alcohol and marriage norms provided men with acceptable excuses for their behaviour, whether it was alcohol consumption, conflicts or self-harm.

Conclusions This study found that participants experienced both alcohol-related and non-alcoholrelated daily life stressors. These two categories of daily life stressors, gender inequalities and alcohol norms should be considered when planning alcohol and selfharm prevention in this setting. Life situations also reflected larger community and structural issues.

\section{Key questions}

What is already known about this topic?

- Alcohol consumption in rural Sri Lanka can cause social and financial strain —and is a major contributor for self-harm and suicide.

- Academics have called for qualitative research to understand the role of alcohol consumption in cases of self-harm and suicide in Sri Lanka.

What are the new findings?

- Two categories of daily life stressors emerged: alcohol-related and non-alcohol-related stressors. Alcohol-related daily life stressors aggravate and complicate non-alcohol-related daily life stressors within marriages and intimate relationships, leading to partner conflict and episodes of self-harm.

- The two categories of daily life stressors disproportionately influence women over men, and challenge their ability to live up to gendered expectations of the marriage or intimate relationships.

- Gendered alcohol and marriage norms provide men with acceptable excuses for their behaviourincluding alcohol consumption, conflict and selfharm - while women are left responsible for their own and their husband's inappropriate behaviour.

\section{Recommendations for policy}

- The dynamics of daily life stressors, gender inequalities and alcohol norms put forward in this study should be considered in future alcohol and self-harm research and interventions in the rural Sri Lankan context.

- Individual level interventions need to be complimented with action at the family and community levels.

\section{INTRODUCTION}

Bhagya (not her real name), a woman in her 40s quoted in the title, was admitted to hospital having self-harmed by swallowing 
animal medication. Strained financially, her family had not been able to complete building their house. Bhagya's husband was a frequent alcohol user and his drinking often led to domestic violence. This, her third incidence of self-harm, happened after a violent conflict between the spouses over a broken phone. Bhagya's everyday life appeared stressful on a number of parameters, which was exacerbated by her husband's alcohol use-a life situation she captured with the statement depicted in the title.

The harmful use of alcohol is a causal factor for many diseases and injuries, and is estimated to result in 5.9\% of all deaths globally. ${ }^{1}$ Alcohol consumption is low in Sri Lanka compared with Western countries but higher than the WHO South-East Asia region average and is estimated to be on the rise. ${ }^{12}$ Such estimates are difficult to make, however, since illicit, unrecorded alcohol is widely consumed in rural Sri Lanka. ${ }^{3}$ In the dry zone of Sri Lanka, the setting for this study, alcohol consumption is a highly gendered, primarily masculine, activity. ${ }^{2}$ It is accepted behaviour during social occasions, although only for men. Female drinking is generally unaccepted and rare. ${ }^{4}$

In addition to physical consequences, harmful use of alcohol is known to pose a socioeconomic burden to the consumer and to individuals around the drinker. ${ }^{5}$ The second highest rate of harm per litre of alcohol is found in South-East Asia, ${ }^{1}$ and in Sri Lanka research shows that harm to families from alcohol misuse includes struggles over economic prioritisation, ${ }^{4}$ domestic violence, loss of status in the community ${ }^{6}$ depression $^{7}$ and even self-harm and suicide. ${ }^{3}$

Sri Lanka was, for a number of years, infamous for its high rate of suicides (51.5/100 000 population in 1995). ${ }^{8}$ However, a significant decline has been seen in recent years $(14 / 100000$ population in 2015), primarily due to regulation of pesticides, ${ }^{9}$ a common method of self-harm in the country. The number of people who self-harm remains alarmingly high, however, and Bhagya described above is one out of an estimated 339 per 100000 individuals who annually self-harm in the Anuradhapura area of Sri Lanka. ${ }^{10}$ Sri Lankan suicide research suggests a link between alcohol, self-harm and suicide. ${ }^{11}$ For example, a psychological autopsy study of suicide in rural Sri Lanka found that $61 \%$ of 293 men who died due to suicide were misusing alcohol. ${ }^{12}$ Additionally, alcohol misuse by a family member was thought to have contributed to the suicide in $14 \%$ of 79 female cases. ${ }^{12}$ A qualitative study exploring narratives of individuals who self-harmed in India found alcohol to be an important feature of underlying problems and a contributor to family tension. ${ }^{13}$ Though this connection between alcohol and self-harm is evident, the social processes around alcohol consumption, self-harm and suicide in Sri Lanka are unclear, and several academics have called for more qualitative research to explore this further. ${ }^{3611}$

To explore experiences of individuals like Bhagya, we qualitatively investigated daily life stressors in marriages and intimate relationships, with a view towards alcohol use and events of self-harm. To reach a comprehensive understanding of such dynamics, we positioned ourselves between disciplines of ethnography and public health.

\section{METHODS}

\section{Key concepts}

Due to the inductive nature of this qualitative study, a predetermined theoretical framework was not applied. Instead, several theoretical and empirical concepts have emerged during the research, as central for the analysis. One key concept is that of everyday life. It entails research of daily life and interactions between individuals, with a focus on perceptions and thoughts of their social situations and relations. ${ }^{14}$ Everyday life research is described as an entrance to understanding larger issues, such as negotiations in marriages and how couples organise their lives together. ${ }^{15}$ In this study, the frame of everyday life is applied to investigate how rural Sri Lankan men and women deal with alcohol consumption, partner conflicts and self-harm in their everyday married or intimate life.

As introduced by Antonovsky, stressors are part of daily life, occurring at different levels and taking different forms. ${ }^{16}$ Partner conflicts and self-harm can be seen as alcohol-related and non-alcohol-related daily life stressors and reactions to them, creating changing pressures on individuals who withstand and deal with them. Stressors can also be non-events, which are unnoticeable and unchangeable conditions of daily life. While much focus in stress research has looked at dramatic, major life events, we here argue that the accumulation of daily hassles also has a great impact on well-being. ${ }^{17}$ In this study, daily life stressors are explored within the context of the marriage or intimate relationship.

Among Sinhalese Sri Lankans, marriage has been explained to institutionalise political, social, economic and moral norms. ${ }^{18}$ Traditionally, a Sri Lankan couple was expected to be of the same socioeconomic status, ethnicity, religion and age. ${ }^{18}$ Marriages can still be arranged by both families, however so-called love marriages, initiated by the couple and not necessarily met with parental disapproval, are an increasing phenomenon. ${ }^{19}$ Premarital, romantic relationships have thus become more common though premarital sex is generally not accepted. ${ }^{20}$ Fear of public shame, lajja-baya or shame-fear, is internalised in Sri Lankan children from an early age ${ }^{21}$ and adherence to gendered norms of respectability is essential when marrying in Sri Lanka. Female behaviour norms comprise shyness, naivety and virginity, ${ }^{21}$ while men should be self-controlled, ${ }^{22}$ guardians of women's behaviour ${ }^{21}$ and strong breadwinners capable of protecting the family. ${ }^{23}$ It is common for the bride to move to the home of the groom after marriage.$^{19}$ Divorce and legal separation are uncommon in Sri Lanka. ${ }^{24}$ Understanding these norms of marriage and intimate relationships is central for understanding the complex dynamics of alcohol, partner conflicts and self-harm. 
Lastly, gendered behaviour is a central concept for this study, when exploring participants' perceptions and explanations of gendered expectations to the marriage. West and Zimmerman described how gender is a continuous social 'doing' embedded in everyday interaction. ${ }^{25}$ Men and women seek to live up to expected 'normal' male or female roles in accordance to context-specific societal expectations. Failure to appropriately 'do gender' can be seen as an act of social deviance. In this study, we seek to explore how men and women 'do gender' in the marriage or intimate relationship, through alcohol use and partner conflicts.

\section{Definition of self-harm}

In this paper, self-harm refers to 'deliberate injury to oneself'. Whereas suicide attempt presumes suicidal intent and that the person 'succeeded' or 'failed' in their actions, ${ }^{26}$ self-harm covers how most deliberate self-harm cases in Sri Lanka are non-fatal and characterised by little or no suicidal intent. ${ }^{27}$

\section{Study design}

This qualitative study is part of a larger research exploring alcohol and self-harm in villages in the North Central and North Western Provinces of Sri Lanka ${ }^{28}$ where rates of suicide are high. ${ }^{29}$ The study was carried out from June 2014 to April 2015. The majority of the population in this area of Sri Lanka is Sinhala Buddhists, rural $(94 \%)^{30}$ and mainly engaged in farming or temporary employment.

\section{The research team}

The research team consisted of medical doctors and social scientists from Sri Lanka and Denmark. Two experienced Sinhala research assistants, male and female, collected data in collaboration with the first author. The male assistant, with more than 25 years of experience in participatory research in the area, provided access to and moderated focus group discussions (FGD). The female assistant, who carried out and interpreted the interviews, had a background in social work and was accustomed to carrying out interviews on sensitive topics. Assistants were thereby both competent and sensitive in their approach; however, it should be noted that the gender figuration of the team might have affected what was said during interviews and FGDs. Interview techniques differed: some were conducted in English by the first author with simultaneous translations and others were conducted in Sinhala by assistants with the first author present to ask clarifying questions.

Carrying out a cross-cultural qualitative study is challenging. ${ }^{31}$ The researchers engaged in this study brought different cultural and professional backgrounds and, thereby, insider and outsider perspectives on the studied issues. This spurred discussion and reflection. Working with interpreters can involve misunderstandings and skewed interpretations of findings. ${ }^{31}$ To address this, research assistants received comprehensive study-specific training. To maintain linguistic richness, all recorded interviews were transcribed verbatim in Sinhala and translated into full-text English. For consistency, the same main investigator was maintained throughout the study.

\section{Sampling}

In total, 44 participants aged 19-69 years were purposively sampled for this study. This included individuals who had experienced alcohol-related events of self-harm ${ }^{19}$ and their family members. ${ }^{25}$ All participants who had previously self-harmed were recruited from two major hospitals in the study area (Anuradhapura Teaching Hospital and Thambuththegama Hospital) between August 2014 and March 2015. The total number of non-fatal selfharm cases registered at these hospitals in the same time period was $1005 .{ }^{32}$ Participants were recruited by research assistants stationed in the study hospitals. No incentives were used to recruit. All participants provided written and verbal consent to be interviewed following discharge from the hospital. Men were selected from the self-harm patients intoxicated with alcohol at the time of admission. Women who mentioned alcohol use in the family was related to their case of self-harm were selected among self-harm patients. In some cases, this was only clear after several interviews. Since alcohol was not a factor in their case of self-harm, five women were excluded from the study after the initial interview. Two men, who initially consented to participate, did not wish to continue the interviews due to time constraints. All participants lived in rural communities.

\section{Narrative, life story interviews}

In-depth, narrative life story interviews were carried out with individuals who experienced alcohol-related events of self-harm ( 9 women and 10 men) and with members of their family (17 women and 8 men). The narrative life story interview was a suitable approach to thoroughly understand the accumulation of daily life stressors that resulted in episodes of self-harm..$^{33}$ Of the case families, 15 were from the North Central Province and 4 from the North Western Province. Individuals who had self-harmed were interviewed thrice ( 2 individuals), twice (6 individuals) or once (11 individuals), and their family members once. Interviews followed a semistructured interview guide, focusing on unfolding the participants' life story, alcohol consumption patterns and self-harm events. A pilot interview was performed in the initial phase of the study to develop the interview guide. Participants were interviewed in their homes or in a quiet place away from family members or neighbours. Individuals who had selfharmed were always interviewed prior to their family members, allowing them to share their own accounts of events. A considerable time was spent with participants in their households and villages during interviews. This contextualised the meanings participants attributed to their surroundings ${ }^{34}$ and helped gain a holistic understanding of how they organised their daily life. Elaborate general observations and interview notes were made during and after interviews, including non-verbal 
expressions and reactions, and continuously discussed among the researchers

\section{Focus group discussions}

The insights gained into marriages and intimate relationships through in-depth interviews were supplemented by FGDs. These were carried out among community members who had not necessarily self-harmed to obtain a broad range of opinions on the topics of daily life, alcohol culture and self-harm. Two pilot FGDs were carried out in the initial phase of the study to adjust interview guides. These were not included in the data set. Ten FGDs were carried out with 83 participants with 6-11 participants in each group. Groups were divided by gender, age and place of residence. By dividing community members into these groups, there was an expectation of greater openness when delving into the issues at hand. Five FGDs were with women and five with men; six were carried out in a rural and four in a semiurban setting; four were with young, and three each with middle-aged and elderly groups of individuals. Vignettes of alcohol-related self-harm scenarios were presented to the groups to spur conversation. One described a conflict between a drunken husband and his wife, followed by the wife self-harming. The other brought up the case of a young couple, where the husband drank heavily and self-harmed after a failed harvest. Vignettes were constructed, but based on realistic scenarios described in literature and previous work in the area.

\section{Data management and analysis}

Each interview lasted between $45 \mathrm{~min}$ and 3 hours with a mean length of $80 \mathrm{~min}$ for individuals who self-harmed and $60 \mathrm{~min}$ for family members. The majority of interviews were audio recorded. In four situations, participants declined recording and elaborate notes were taken. All interviews were verbatim transcribed in Sinhala and then translated to English by trained translators. An inductive content analysis was applied. ${ }^{34}$ Transcriptions and observational notes were read repeatedly and a detailed timeline of each life story was developed, paying attention to summarising important events, notably, conflicts and daily life stressors; patterns in alcohol use and socioeconomic conditions; and specifics associated with the event of self-harm. Emerging cross-cutting themes, such as differences in gender norms within the marriage, were triangulated with FGDs and contextual data and continuously clarified through discussions within the research team. To ensure validity of the analysis, empirical findings were triangulated with theoretical sources. For example, the concept by West and Zimmerman of 'doing gender' was instrumental for explaining gendered conflicts, alcohol behaviours and their relation to self-harm.

\section{Research ethics}

The study conformed to the Helsinki Declaration. Informed consent was obtained in writing from participants in the narrative, life story interviews and verbally from participants in the FGDs. Participants were informed that their involvement would be confidential and that they could withdraw from the study at any time. They received information about psychosocial support (from the non-governmental organisation 'Women in Need', counsellors at hospitals and the telephone counselling service 'CCCline'). To safeguard their confidentiality, participants are presented anonymously in this presentation.

Interviews can be upsetting to individuals who have selfharmed. Findings from other studies, however, suggested that individuals were likely to feel beneficial from such participation. ${ }^{35}$ A visual analogue scale ${ }^{35}$ was administered before and after interviews with individuals who had self-harmed to assess the effect of being interviewed and identify individuals in profound emotional distress. Of individuals who had self-harmed, 13 reported feeling better, 6 mentioned no difference and none mentioned feeling worse after being interviewed. This reaffirmed the impression that participants generally appreciated the interviews. Nonetheless, we carefully followed up with three participants who appeared especially distressed, referring them to mental health services at hospitals.

\section{FINDINGS}

While each narrative had its own characteristics, common features surfaced. Seventeen of the 19 cases of self-harm were initiated by a conflict with a partner within the marriage or intimate relationship. What first appeared to be trivial explanations of self-harm proved much more complex when narratives unfolded and participants described what could be seen as a number of gendered daily life stressors influencing their situation.

\section{Living extreme everyday lives}

A conflict between spouses played a central role in triggering self-harm, but concurrently all case families lived extreme everyday lives, burdened by a combination of past and present stress factors, including insecurity in terms of income and employment. How mundane or overwhelming the stressors might seem, over time and in combination they played a notable role in the individuals' lives influencing their well-being. In this study, we focus specifically on how such daily life stressors occurred within the marriage or intimate relationship and how they were influenced by alcohol. Examples of this are illustrated in the following two scenarios.

A 38-year-old woman had received limited parental support, abuse by a stepfather and later by two heavy alcohol-drinking ex-husbands. To escape this, she had recently started a new life with another man and they now lived as spouses with her three children, the youngest with mental disabilities. The couple had a fight concerning the teenage daughter. While drunk, the man blamed his partner for the daughter's promiscuous behaviour noting how their relatives would speak badly about them. 
This turned into a violent fight followed by the woman ingesting pesticides.

Living alone with his two sisters, a 19-year-old man was juggling a range of stressors. As a child, his father died from suicide and his mother moved overseas to earn for the family. The young man explained how he was in a relationship with a girl against the will of both families who deemed it inappropriate. Her grandmother had filed a police complaint against him because her granddaughter was under age. This complaint prevented him from pursuing a dream career in the army. Due to rumours about his girlfriend seeing someone else, he spent an entire day drinking beer with his friends and eventually consumed pesticides to self-harm.

These two cases exemplify how a woman and a man experienced both alcohol-related and non-alcohol-related daily life stressors. Though the cases had different characteristics, alcohol aggravated the overall level of stress for both of them. The two scenarios also exemplify how alcohol consumption patterns differed among participants. Among all interviewed men, two explained how they engaged in daily, heavy drinking and their partners described it as a dominant, daily hassle. All other men described their alcohol use as social and occasional drinking: drinking in evenings after work with other men in the village and at important social occasions, such as weddings. Though their alcohol drinking took place in a social, acceptable setting, alcohol was continuously explained to result in harm to the drinker, and wives and children in the form of domestic violence and insecurity, financial instability and shame. Young women in an FGD mentioned how: "drinking creates lots of problems. It is the foundation of every problem." This reinforced our observations that alcohol consumption, no matter its form, seemed to aggravate the daily life stress encountered within marriages and intimate relationships.

\section{Gendered marriage expectations}

In conjunction with the different alcohol-related stressors, participants in FGDs and the case families continuously highlighted gendered expectations to their roles and responsibilities of their marriage or intimate relationships. Difficulties in living up to these expectations sparked conflicts and self-harm.

\section{Practising an appropriate, gendered behaviour}

In the majority of narratives, it was highlighted how clashes occurred between partners because women were perceived not to conduct themselves appropriately within the marriage or intimate relationship. This entailed being a patient, obedient wife, silently bearing up under problems. The following case illustrates the diverse expectations of a young, newly wedded woman. Her daily life stressors were exacerbated by her husband's daily consumption of alcohol, which eventually led her to self-harm.

The 24-year-old woman had recently married and moved into her family-in-law's household. She explained what could be characterised as a number of stressors in her daily life. Behaving in a shame-fear manner, she explained how she was suffering from 'fits' (a form of epilepsy), had a hard time remembering, easily got tired and described herself as inept. She had previously selfharmed thrice. Precipitating one of the episodes was her mother-in-law scolding her for not contributing enough to the household: "they shouted at me and told me that I am doing nothing." Being scared how a pregnancy would affect her illness, she was secretly using contraception. Her husband often drank alcohol and when he came home drunk in the evening he blamed her for not having any children yet. She explained how this blame made her feel depressed. Usually she was quiet during such accusations, but on the night of the latest case of self-harm , she "lost her temper [and] couldn't withstand it anymore." Consequently, she swallowed some of the medicine she took to control her illness. After the self-harm episode her in-laws and husband told her to bear up under the problems in her marriage and "(...) to be patient despite whatever the things other people say."

This case illustrates how the young woman was blamed for not living up to expected norms of marriage by neither taking sufficient care of the household nor being able, or willing, to conceive. These daily life stressors combined with her husband's alcohol drinking caused her 'loss of temper' and she expressed the injustice done to her by self-harming. After the self-harm, her husband's alcohol drinking reduced and the family took better care of her. The self-harm thus resulted in positive benefits to her.

Women's incapability of living up to female norms of 'bearing up under the problems' of daily life was an explanation for self-harm in the above and many similar narratives. When presented with a vignette about a woman who self-harmed after fighting with her drunken husband, both young and elderly women in FGDs elaborated on how 'such a wife' (who would self-harm) was selfish and that:

She did not think about her children, she only thought about her [own] life. So, she is wrong. This proves that she does not have strength to bear up under things. Though we are confronted with a lot of problems, we, as mothers, should sacrifice our lives for our children.

This quote illustrates how Sri Lankan mothers were expected to be self-sacrificing, minding their family's well-being before themselves. Highlighting one's own needs was thereby not within the frame of acceptable behaviour. To be patient and accepting towards spouses' alcohol consumption was also a distinct female norm. The socially appropriate strategy, as highlighted across age, gender, FGDs and narratives, was to stay silent in order to avoid conflicts. Middle-aged men in an FGD explained how it would generally create trouble to discuss matters with a drunken man. The wife of a 36-year-old shop owner mentioned how: "I don't talk with him when he comes home after he has been drinking. Then we start to argue." Middle-aged men in an FGD further highlighted that in 
addition to staying silent when their spouses were intoxicated, women were also expected to ensure that their husbands stopped drinking. The incapability of changing husbands' alcohol behaviour, however, was mentioned by many women.

Though all interviewed wives expressed a continuous effort to conform to norms of 'bearing up under problems' silently and strategically, they were in several cases blamed as the single cause of the marital conflict in their own or husband's case of self-harm. More specifically, in the conflict situation they violated the norms of proper behaviour and did "not stay silent anymore." In five of the 10 narratives with men, it was mentioned how the event of self-harm was influenced by their wives' questioning of their fidelity. A 35-year-old schoolteacher said he self-harmed due to his wife's shameful accusations of him having affairs. Similarly, a 48-year-old man doing daily wage work mentioned how his wife's suspicion after a phone call from an unknown woman was the reason for his self-harm episode: "She shouted at me saying that I have another affair, [and] so on." After the conflict, he drank by himself and then self-harmed by swallowing 15 allergy tablets. That women openly questioned men's moral behaviour appeared to be a recurring factor in these explanations of self-harm. This was given more emphasis in interviews than whether the men actually did have affairs, which the words 'another affair' could refer to.

In general, spouses and community members perceived it to be wrong for both genders to display emotions and lose control. They described their marital conflicts, emotional outbursts and self-harm with being "overwhelmed by anger," as if these emotions came to them from the outside, justifying their cause for self-harm by highlighting their 'wrong' and externalised emotions and not as an end-result of stressful and unfortunate life situations. Being under the influence of alcohol was similarly explained as 'not being in control of oneself' and thus excused men's outbursts of anger and episodes of selfharm. As a 36-year-old shop owner who was drunk at his time of self-harm said: "I wasn't in my right senses... that's why I did it [self-harm]." Alcohol drinking thereby became a way for men to disregard their actions, including selfharm, leaving their behaviour out of their hands.

\section{His drinking, her distress}

There was a common understanding among both genders in the FGDs that a man's alcohol drinking was especially shameful for wives. In an FGD with elderly men in a semiurban setting, one explained how events following alcohol drinking could even be an "assassination of her character" and result in difficulties for the whole family. Domestic violence was an evident part of everyday lives in eight of the nine women's self-harm narratives. The violence spanned from occurring occasionally to being a daily event. Alcohol was often involved and women in an FGD explained how it was the worst consequence of the drinking. What mainly shook the moral institution of the marriage was not the domestic violence itself however, but the shame attached when it occurred in public. A response to this shame was self-harm as was the case for the 30-year-old woman in the following case.

She emphasised her good relationship with her husband. However, when he drank she noted that: "my husband does not drink regularly, but when he is drunk it is really difficult to control." Preceding her case of self-harm, the whole family attended a wedding. The wife wanted to go home with the children and though it was socially unacceptable for her to walk home alone, her intoxicated husband refused to leave with her. Initially she kept quiet knowing his temper when drunk. After asking him again, they started fighting and he hit her in front of the other guests. This was extremely shameful for her. She walked home with the children and when her husband returned, she pretended to drink pesticides in front of him and was later taken to the hospital by family members.

This case illustrates a clash of expectations. It was anticipated that the husband would be drinking with the other men, while his wife expected him to live up to the notions of being a good husband and father. The woman felt ashamed for being hit in public, and also in how she was left uncared for. It was, however, problematic for her, and other women, to verbalise this. What is noteworthy is that the woman did not have to drink the pesticides to gain an effect. It was sufficient to pretend, thereby scaring her husband and showing her discontent for his actions.

The women's narratives generally highlighted unfulfilled expectations to their husbands' responsibilities within the marriage. Men's inability or unwillingness to care for their families explained the conflicts and self-harm in five of the nine women's self-harm cases. More specifically, men's alcohol use led to what could be explained as stressful non-events for the wives, when husbands failed to prioritise and take action about their family's well-being.

This was the case for a 42-year-old woman. She lived with her husband, a heavy alcohol user, and their youngest daughter. The wife was responsible for their finances, trying to save up for unforeseen expenses. This was made difficult by her husband's heavy alcohol use. A daily hassle was her husband asking her for money to buy alcohol. At one visit we sat in the living room, furnished with appliances brought home from her time in the Middle East. The husband was lingering outside and called for her. Afterwards she explained how he asked for money for alcohol and how she was afraid to refuse him.

This negotiation about alcohol expenditure exemplifies several issues. The husband was not the main breadwinner, but in a position of inferiority, pleading for pocket money. Meanwhile, the wife was not in a position to challenge the supposed patriarch in the family about his spending, which would have been seen as an unacceptable behaviour. Instead, several women explained how they resorted to self-harm in order to "teach him a lesson" and thereby change their husbands' alcohol behaviour. Although probably only in the short run, this 
strategy actually worked according to seven of the interviewed women.

\section{DISCUSSION}

Daily life stressors have been used to illuminate conflicts in marriages and intimate relationships in rural Sri Lanka. Focusing particularly on aspects of alcohol use, dynamics within marriages and intimate relationships, including partner conflicts and episodes of self-harm were explored. Two categories of stressors emerged which influenced participants' life situations; alcohol-related and non-alcohol-related daily life stressors. The alcohol-related daily life stressors aggravated and complicated the already existing stressors within the marriages and intimate relationships.

Previous research in the study area has shown a connection between poorer socioeconomic status and self-harm. ${ }^{10}$ The participants in this study did live under extremely difficult socioeconomic circumstances, with poor quality of housing, job uncertainty and lack of access to basic services. Hence, the observed daily life stressors in this study, including alcohol consumption, mirror larger socioeconomic and structural issues. Further, a profound inequality between genders and difficulties in conforming to gendered expectations in the marriage or intimate relationship were evident. Women encountered both categories of daily life stressors with far greater strength than men, and when husbands consumed alcohol women's situations were complicated further. For men, it was generally acceptable to consume alcohol and they could, to a large extent, blame any 'uncontrolled behaviour,' including self-harm, to an alcohol-induced state of mind.

When women in this study were 'getting filled up by anger,' their expected behaviour or their way of 'doing gender' was challenged. Being subordinate to their husbands, it is inappropriate for women in this setting to express forms of protest or complaint directly. ${ }^{22}{ }^{36}$ Along those lines, Jordal et al noted how women employed in the free-trade zones in Sri Lanka feared ridicule if not conforming to proper behaviour ${ }^{37}$ or 'doing gender' appropriately. Portraying themselves with shame-fear and 'ignorant' of sexual matters, these women avoided judgement, knowing that the family's honour and status were closely linked to their reputations. Similarly, in the present study, women were expected to take on a submissive role in relation to their spouses, even when dealing with violent alcohol problems, in order to conform to norms of female respectability.

In this study, men were expected to participate in alcohol drinking and be protectors of the family. Though conflicting, both features, as Gamburd also noted, seemed important in 'doing' masculinity. ${ }^{4}$ Further, being accused of infidelity was described to justify several cases of men's self-harm. Hewamanne has explained how norms of appropriate Sinhalese Buddhist male behaviour are challenged when giving in to sexual temptation. ${ }^{38}$ It seemed that the accusation of infidelity in itself was enough to make the men fail in 'doing gender' properly. However, the husbands appeared to downplay their own behaviour in the episode and transfer it to be a consequence of their wives' challenging, inappropriate outbursts.

Additionally, an alcohol-induced state of 'unconsciousness' was used as an explanation of men's actions, including their episodes of self-harm. Others have noted how many societies see alcohol use as a 'time out period' or social space that allows for otherwise unacceptable behaviour. ${ }^{39}$ Though certain limits of appropriate consumption behaviour did exist, men were to a large extent dismissed from their responsibilities and actions in their alcohol-induced 'time-out period'. Instead, their behaviour to a large degree seemed to become their wives' responsibility.

Having no gender appropriate 'time out period' women in this study were left with minimum opportunities to break from their daily life stressors. Self-harm thereby became a way to escape a shameful and stressful situation and maybe momentarily better their situation. This goes in line with other suicide researchers' findings that self-harm in Sri Lanka is a method to communicate distress and regain control ${ }^{2636}$ in a context where open expression of anger or distress is unthinkable. ${ }^{40}$ In this regard, we note that the majority of women in this study explained how they contemplated migrating or had already migrated for work, a common phenomenon in Sri Lanka. While the motive for migration is often explained to be financial advancement, it has also been described as an accepted way of leaving stressful marriages. ${ }^{41}$ Such out of household employment opportunities have improved the situation for many Sri Lankan women, but whereas their migration can be viewed as a self-sacrificing act and a way to care for their children, the women are also violating gendered norms of the marriage in leaving their households behind. The act furthermore challenges men's masculinity-if they were providing for their families as supposed to, the women were not 'forced' to move abroad. Women's migration thereby plays a role in both maintaining and challenging traditional gender and marriage norms.

\section{CONCLUSION}

This study explored daily life stressors among men and women in rural Sri Lanka, who experienced an alcohol-related event of self-harm. Two categories of daily life stressors influenced the participants' lives: alcohol-related and non-alcohol-related stressors. The alcohol-related daily life stressors aggravated and complicated non-alcohol-related daily life stressors within marriages or intimate relationships, which led to marital conflict and episodes of self-harm. Strongly gendered alcohol and marriage norms provided men with culturally acceptable excuses for their behaviour, whether it was alcohol consumption, conflicts or self-harm. Women were often blamed for their own and husbands' behaviour and 
appeared to have no culturally appropriate methods of expressing distress that led to self-harm. These dynamics of daily life stressors, gender inequalities and alcohol norms should be considered in future alcohol and self-harm research and interventions in the rural Sri Lankan context. In conclusion, it should be noted how the marriages and intimate relationships broad forward are reflective of larger community and structural issues that call for a reform in areas such as gender inequality, poverty and underemployment.

Acknowledgements Most importantly, we are grateful to the Sri Lankan men and women who generously led us into their lives, telling us their stories. We would like to truly thank the research assistants Chandima Jayasena and Ravi Pieris who played a major role in carrying out the study as well as Surani Neangoda, Chathumini Rathnapala and Prabash Siriwardhana who verbatim translated the audio-recorded interviews. We further thank all South Asian Clinical Toxicology Research Collaboration (SACTRC) staff, especially Chamil Kumara, Manjula Weerasinghe, Indunil Abeyrathna and Melissa Pearson, as well as the staff at the Department of Community Medicine, Faculty of Medicine and Allied Sciences, Rajarata University of Sri Lanka, especially Professor Suneth Agampodi. We thank Safe Storage Trial for access to data (Wellcome Trust GR090958). Finally, we thank the three reviewers who gave knowledgeable comments and input to an earlier version of this paper.

Contributors JBS, TR and FK collaborated on conceptualising and designing the study and organising data collection. JBS carried out data collection, data analysis and drafting of the manuscript. TR and FK took part in analysis and drafting of the manuscript. BRS provided input to methodology and background information on the study site. TA and SS contributed to the context and cultural specificities, methodology, ethical considerations and initial analysis. All authors read and approved the final manuscript.

Funding This study was carried out with financial support from the University of Copenhagen, Denmark; Christian og Ottilia Brorsons Rejselegat for yngre videnskabsmænd og kvinder; Augustinus Fonden; Oticon Fonden; and Direktør Jacob Madsen og Hustru Olga Madsens Fond. None of the funding bodies played any role in the design of study or analysis of data.

Competing interests None declared.

Ethics approval Ethics Review Committee, Faculty of Medicine and Allied Sciences, Rajarata University of Sri Lanka (ERC/2014/014).

Provenance and peer review Not commissioned; externally peer reviewed.

Data sharing statement № additional data are available.

Open Access This is an Open Access article distributed in accordance with the Creative Commons Attribution Non Commercial (CC BY-NC 4.0) license, which permits others to distribute, remix, adapt, build upon this work non-commercially, and license their derivative works on different terms, provided the original work is properly cited and the use is non-commercial. See: http://creativecommons.org/ licenses/by-nc/4.0/

(C) Article author(s) (or their employer(s) unless otherwise stated in the text of the article) 2017. All rights reserved. No commercial use is permitted unless otherwise expressly granted.

\section{REFERENCES}

1. World Health Organization. Global status report on alcohol and health, 2014. Geneva: World Health Organization, 2014.

2. Zavos HM, Siribaddana S, Ball HA, et al. The prevalence and correlates of alcohol use and alcohol use disorders: a population based study in Colombo, Sri Lanka. BMC Psychiatry 2015;15:158.

3. Jayasinghe NR, Foster JH. Deliberate self-harm/poisoning, suicide trends. The link to increased alcohol consumption in Sri Lanka. Arch Suicide Res 2011;15:223-37.

4. Gamburd M. Breaking the ashes - the culture of illicit liquor in Sri Lanka. Ithaca, New York: Cornell Univeristy Press, 2008.

5. Room R, Ferris J, Laslett AM, et al. The drinker's effect on the social environment: a conceptual framework for studying alcohol's harm to others. Int J Environ Res Public Health 2010;7:1855-71.

6. Konradsen F, Hoek W, Peiris P. Reaching for the bottle of pesticide-a cry for help. Self-inflicted poisonings in Sri Lanka. Soc Sci Med 2006;62:1710-9.
7. Ariyasinghe D, Abeysinghe R, Siriwardhana $P$, et al. Prevalence of major depressive disorder among spouses of men who use alcohol in a rural community in central Sri Lanka. Alcohol Alcohol 2015:50:328-32.

8. Knipe D, Metcalfe C, Gunnell D. WHO suicide statistics - a cautionary tale. Ceylon Med J 2015;60:35.

9. Knipe DW, Chang SS, Dawson A, et al. Suicide prevention through means restriction: impact of the 2008-2011 pesticide restrictions on suicide in Sri Lanka. PLoS One 2017;12:e0172893.

10. Knipe DW, Gunnell D, Pieris R, et al. Is socioeconomic position associated with risk of attempted suicide in rural Sri Lanka? A cross-sectional study of 165000 individuals. BMJ Open 2017;7:e014006

11. Pearson M, Zwi AB, Rouse AK, et al. Taking stock - what is known about suicide in Sri Lanka: a systematic review of diverse literature. Crisis 2014;35:1-12.

12. Abeyasinghe R, Gunnell D. Psychological autopsy study of suicide in three rural and semi-rural districts of Sri Lanka. Soc Psychiatry Psychiatr Epidemiol 2008;43:280-5.

13. Parkar SR, Dawani V, Weiss MG. Gender, suicide, and the sociocultural context of deliberate self-harm in an urban general hospital in Mumbai, India. Cult Med Psychiatry 2008;32:492-515

14. Douglas JD, Adler P, Fontana A, et al. Introduction to the sociologies of everyday life. Boston, London, Sydney, Toronto: Allyn and Bacon, Inc, 1980

15. Löfgren O, Life E. Anthropology of Everyday Life. International encyclopedia of the social and behavioral sciences: Elsevier, 2015:323-6. http://linkinghub.elsevier.com/retrieve/pii/ B9780080970868120689

16. Antonovsky A. Health, stress and coping. San Francisco: JosseyBass Publishers, 1980

17. Kanner AD, Coyne JC, Schaefer C, et al. Comparison of two modes of stress measurement: daily hassles and uplifts versus major life events. J Behav Med 1981;4:1-39.

18. Sørensen BR. Relocated lives: displacement and resettlement within the Mahaweli project, Sri Lanka. Amsterdam: VU University Press, 1996.

19. Chapin BL. Childhood in a Sri Lankan village. New Brunswick, New Jersey, London: Rutgin University Press, 2014.

20. Hewamanne S. Suicide narratives and in-between identities among Sri Lanka's factory workers. Ethnology 2010;49:1.

21. Obeyesekere G. The cult of the goddess Pattini. Chicago: University of Chicago Press, 1984

22. Spencer J. Collective violence and everyday practice in Sri Lanka. Mod Asian Stud 1990;24:603-23.

23. Jordal M, Wijewardena K, Öhman A, et al. Disrespectful men, disrespectable women: men's perceptions on heterosexual relationships and premarital sex in a Sri Lankan free trade zone - a qualitative interview study. BMC Int Health Hum Rights 2015;15:3.

24. Department of census and statistics - Sri Lanka. Nuptiality. 2012 http://www.statistics.gov.lk/Abstract2015/CHAP3/3.14.pdf

25. West C, Zimmerman DH. Doing gender. Gender \& Society 1987;1:125-51

26. Marecek J, Senadheera C. 'I drank it to put an end to me': narrating girls' suicide and self-harm in Sri Lanka. Contrib Indian Sociol 2012;46:53-82

27. Eddleston M, Sheriff MH, Hawton K. Deliberate self harm in Sri Lanka: an overlooked tragedy in the developing world. BMJ 1998;317:133-5.

28. Sørensen JB, Rheinländer T, Sørensen BR, et al. An investigation into the role of alcohol in self-harm in rural Sri Lanka: a protocol for a multimethod, qualitative study. BMJ Open 2014:4:e005860.

29. Knipe DW, Padmanathan P, Muthuwatta L, et al. Regional variation in suicide rates in Sri Lanka between 1955 and 2011: a spatial and temporal analysis. BMC Public Health 2017;17:193.

30. Department of Census \& Statistics, Ministry of Policy Planning and Economic Affairs. Census on population and housing 2012. Battaramulla, Sri Lanka: Department of Census \& Statistics, 2012. http://www.statistics.gov.Ik/PopHouSat/CPH2011/index.php? fileName=FinalReportE\&gp=Activities\&tpl=3

31. Liamputtong P. Performing qualitative cross-cultural research. UK: Cambridge University Press, 2010.

32. Pearson M, Metcalfe C, Jayamanne S, et al. Effectiveness of household lockable pesticide storage to reduce pesticide selfpoisoning in rural Asia: a community-based, cluster-randomised controlled trial. Lancet 2017;390:1863-72.

33. Atkinson R. The life story interview. California, United States of America: SAGE Publications, Inc, 1998. http://methods.sagepub. com/book/the-life-story-interview.

34. Bryman A. Social research methods. New York: Oxford University Press, 2008. 
35. Biddle L, Cooper J, Owen-Smith A, et al. Qualitative interviewing with vulnerable populations: individuals' experiences of participating in suicide and self-harm based research. $J$ Affect Disord 2013:145:356-62.

36. Widger T. Suffering, frustration, and anger: class, gender and history in Sri Lankan suicide stories. Cult Med Psychiatry 2012;36:225-44.

37. Jordal M, Wijewardena K, Ohman A, et al. Negotiating respectability: migrant women workers' perceptions of relationships and sexuality in free trade zones in Sri Lanka. Health Care Women Int 2014;35:658-76.
38. Hewamanne S. Respectable gentlemen and street-savvy men: HIV vulnerability in Sri Lanka. Med Anthropol 2017;36:744-57.

39. Peralta RL. Alcohol allows you to not be yourself: toward a structured understanding of alcohol use and gender difference among gay, lesbian, and heterosexual youth. J Drug Issues 2008;38:373-99.

40. Spencer J. A sinhala village in a time of trouble. Oxford University Press: Oxford, 1990.

41. Gamburd M. The kitchen spoon's handle - transnationalism and Sri Lanka's migrant housemaids. New York: Cornell University Press, 2000. 